\title{
FALSAS ETIMOLOGÍAS EN EL DERECHO, EL CASO DE LAS INSTITUCIONES DE GAYO
}

\author{
False Etymologies in the Law: The Case of the Institutions of Gaius
}

Henry Campos Vargas ${ }^{1}$

A Mercedes, mi madre.

\begin{abstract}
RESUMEN
El presente artículo procura mostrar la importancia que tuvo para los antiguos romanos el comprender el origen de los términos legales. Con este propósito, se han identificado diferentes etimologías ofrecidas por Gayo en sus "Instituciones", y se han corregido cuando ha sido necesario.
\end{abstract}

Palabras clave: Gayo, derecho romano, etimología, vocabulario legal, instituciones.

\begin{abstract}
This paper shows the importance for Ancient Romans to understand the origin of legal terms. We have identified different etymologies given for Gaius in his Instituta and correct them when it was necessary.
\end{abstract}

Key Words: Gaius, Roman Law, etymology, legal terms, institutions.

\footnotetext{
${ }^{1}$ Universidad de Costa Rica. Profesor catedrático de la Escuela de Filología, Lingüística y Literatura. Costa Rica. Correo electrónico: hcamposv@yahoo.es

Recepción: 4/4/17 Aceptación: 25/4/17.
} 


\section{Introducción}

El discurso jurídico es una de esas construcciones humanas con propiedades reflexivas. Construido a base de palabras, la preocupación por su significado es recurrente, en virtud por las importantes implicaciones económicas y sociales que su uso conlleva.

Algunas voces se han conservado a través del paso de los siglos en Roma en la Ley de las Doce Tablas, pese a llegarse a desconocer su significado. Tal es el caso del licium del que se nos ha transmitido:

Quid sit autem licium, quaesitum est, sed uerius est consuti genus esse quo necessariae partes tegerentur (III, p. 193).

Se ha preguntado qué es el licium, mas, con toda seguridad, es un tipo de mandil con el que se cubrían las partes necesarias.

Ante una acusación por furtum quienquiera que desee hacer la búsqueda en el domicilio del acusado, ingrese desnudo con un licium atado a la cintura y sosteniendo un plato: de encontrar lo que fue robado, el hurto sería manifiesto.

En otros casos, se recurre a precisiones conceptuales como en III, 217 al exponerse el tema del damnum:

Si quid enim ustum aut ruptum aut fractum fuerit, actio hoc capite constituitur, quamquam potuerit sola rupti appellatio in omnes istas causas sufficere; ruptum enim intellegitur quod quoquo modo corruptum est. Vnde non solum usta aut rupta aut fracta, sed etiam scissa et conlisa et effusa et quoquo modo uitiata aut perempta atque deteriora facta hoc uerbo continentur.

$\mathrm{Si}$ algo fuera quemado, destruido o roto, se establece una acción en este capítulo, aunque la sola denominación de "roto" podría bastar para todas estas figuras: "roto" ciertamente lo que ha sido destruido de cualquier manera. De donde no solamente "quemado", "roto" o "quebrado", sino también "rasgado", "golpeado" o "derramado" o "echado a perder de cualquier forma", "suprimido" o "deteriorado" se comprende en esta palabra.

O bien, igualmente se encuentran casos de definiciones por medio de la ejemplificación, como en el siguiente caso de la iniuria:

Iniuria autem committitur non solum cum quis pugno puta aut fuste percussus uel etiam uerberatus erit, sed etiam si cui conuicium factum fuerit, siue quis bona alicuis quasi debitoris sciens eum nihil sibi debere proscripserit, siue quis ad infamiam alicuis libellum aut carmen scripserit, siue quis matrem familias aut praetextatum adsectatus fuerit, et denique aliis pluribus modis (III, p. 220). 
La iniuria se comete no solo cuando alguien golpea con el puño o un palo, o azota a alguien, sino también si se le hiciera un escándalo a alguien, ya si alguien anunciara la venta de los bienes de alguien como deudor, sabiendo que no le debe nada; ya si alguien escribiera un libelo o poema para infamar a una persona, ya si asediara a una mater familias o a un joven, y, en fin, de muchas otras formas.

O también este otro en el que se precisa la noción de "arma":

Armorum autem appellatione non solum scuta et gladios et galeas significari intellegemus, sed et fustes et lapides (IV, p. 155).

Con la denominación de arma no solo nos referimos a los escudos, las espadas y los cascos, sino también a los palos y las piedras.

\section{La etimología}

De acuerdo con el diccionario de la Real Academia de la Lengua Española (2001), la etimología trata del: "Origen de las palabras, razón de su existencia, de su significación y de su forma" (p. 924).

Frente a esta primera acepción existe otra de raigambre popular, también reconocida por la Academia:

Interpretación espontánea que se da vulgarmente a una palabra relacionándola con otra de distinto origen. La relación así establecida puede originar cambios semánticos (v. por ej. miniatura) o provocar deformaciones fonéticas (v. por ej. antuzano y altozano) (ibid).

En el presente trabajo, se hará uso de ambos sentidos para explorar la riqueza de las aproximaciones que en el derecho romano se hicieron.

Desde un punto de vista lógico, el tema de las etimologías plantea un problema de tautología, o, si se quiere, de redundancia. Esto obedece a que el significante léxico suele encontrarse en ambos extremos de la ecuación, es decir, tiende a aparecer tanto en el vocablo de origen como en el derivado. Considérese el siguiente ejemplo:

tablita<tabla

La relación etimológica entre tabla y tablita es obvia, empero, pone de manifiesto la formación derivativa mediante el empleo de sufijos que forman diminutivos en español. 
Ahora bien, atiéndase a esta otra enunciación con la segunda de aquellas palabras:

$$
\text { tabla<tabula }
$$

Aunque semánticamente se expresa el mismo concepto en cada uno de los extremos del enunciado (lo que implicaría una tautología o, si se quiere, una redundancia), hay información asociada de importancia: la síncopa postónica en la sílaba -bu-, fenómeno, además, frecuente en el proceso de evolución del latín al español.

Por lo anterior, la doble aparición del significante léxico no es por este solo hecho trivial, sino que, por el contrario, su examen y concienciación tiende a enriquecer el conocimiento que se tiene de una determinada palabra, así como de su familia léxica.

Lo anterior muestra, parece, que las tautologías y las redundancias no siempre son vicios del lenguaje ni del pensamiento.

Ya es un atavismo en la cultura occidental reconocer que una de las mayores contribuciones de Roma ha sido el aporte del derecho.

Por tratarse de una fuente primaria para el estudio y conocimiento del derecho romano, este trabajo centra su atención en las Instituciones de Gayo.

\subsection{Comentario Primero}

Ya en el propio inicio del Comentario Primero de su obra (compuesta de cuatro comentarios) la relación etimológica salta a la vista:

Quisque populus ipse sibi ius constituit, id ipsius proprium est uocaturque ius ciuile, quasi ius proprium ciuitatis (I, p. 1).

Cada pueblo ha establecido su derecho, este es para sí mismo y se llama derecho civil, como si fuera el derecho propio de la ciudad.

La relación este ciuile/ciuitas es patente: el derecho civil es el derecho propio de cada ciudad, a partir del significante léxico ciui-. Sin embargo, ciuile proviene propiamente de ciuis, es decir, ciudadano, porque es el derecho que los ciudadanos, organizados en una comunidad política, se dan a sí mismos. Es a partir de esta base individual que se construye la ciudad. 
Cabe apuntar que el sufijo -ilis permite en latín formar adjetivos a partir, ya sea de sustantivo, ya de otros adjetivos. Este sufijo expresa la idea de relación, conformidad o semejanza.

El complemento del derecho civil es el ius gentium, el derecho de gentes, que ocupa el segundo lugar de las once etimologías del presente comentario. De acuerdo con el autor, consiste en:

Id apud omnes populos paraeque custoditur uocaturque ius gentium, quasi quo iure omnes gentes utuntur (ibid).

Ese [derecho] se sigue entre todos los pueblos por igual y se llama ius gentium, es decir, como si todas las gentes usaran tal derecho.

Gentium es el genitivo plural de gens (gentes en nominativo plural), las gentes, el mundo. Se trata, pues, de la misma e idéntica voz, por lo que la explicación etimológica es de naturaleza causal.

Estas relaciones etimológicas, así como muchas otras, son afortunadas en la inteligencia gayana, empero, no siempre es así. El presente trabajo rescata unas y otras para establecer un contraste en el examen lingüístico de Gayo, quien siempre, en procura de claridad didáctica, ofrece imágenes vívidas y plásticas a sus lectores.

Once son en total las referencias de esta naturaleza en este primer comentario, dedicado al derecho de las personas. Sobre el tema de la filiación por vía paterna, al considerar a aquellos hijos de padre incierto, se expresa:

Hi patrem habere non intelleguntur, cum is et incertus sit; unde solent spurii

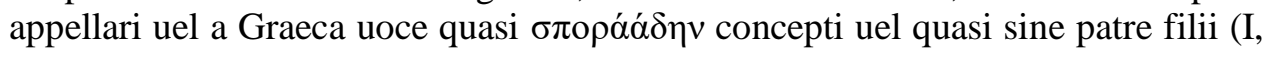
p. 64).

Estos no se considera que tengan padre, puesto que él es incierto; de donde suelen

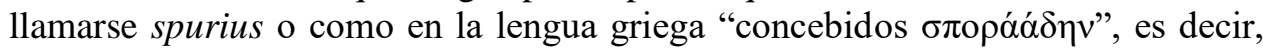
como hijos sin padre.

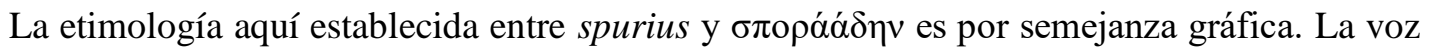
griega es un adverbio que significa aquí y allá, separadamente, en alusión a la indeterminación paterna. Ernout y Meillet (1959, p. 645), en cambio, explican que podría estar asociado a la voz sabina neutra spurium, denominación de los genitales femeninos; así como lo vinculan posiblemente con el etrusco a través de la familia léxica de spurcus, sucio, en latín.

Más adelante, al tratar el tema de la adopción, se ofrece otra curiosa relación: 
Populi auctoritate adoptamos eos qui sui iuris sunt: quae species adoptionis dicitur adrogatio, quia et is qui adoptat rogatur, id est interrogatur, an uelit eum quem adoptaturus sit iustum sibi filium esse, et is qui adoptatur rogatur, an id fieri patiatur, et populus rogatus, an id fieri iubeat (I, p. 99).

Por la autoridad del pueblo adoptamos a aquellos que son sui iuris: el tipo de adopción se llama adrogatio, porque en ella, quien adoptad es "rogado" a ello, esto, es interrogado sobre si quiere que quien va a adoptar sea su hijo legítimo; mientras que a quien es adoptado se le pregunta si quiere serlo, así como al pueblo se le pregunta si ordena que esto se realice.

Aquí es clara la composición preposicional ad+rogatio en la voz, apropiadamente expresada en la explicación gayana. De tal forma, se obtiene el verbo arrogo, adoptar; el que, mediante el sufijo -tio (que sirve para expresar una acción) produce la voz que nos ocupa.

Un mecanismo semejante de derivación se encuentra en la confarreatio, una de las diversas formas por las que una mujer puede entrar en la manus de un varón. Como bien expresa Gayo, su nombre procede del pan farreo ofrecido ceremonialmente a Júpiter Farreo (I, p. 112) al que se ha añadido la preposición cum. De aquí procede el verbo cunfarreo, casarse.

En cambio, para la coemptio, mecanismo también establecido para la institución de la manus, nuestro autor lo describe así:

Coemptione uero in manum conueniunt per mancipationem, id est per quamdam imaginariam uenditionem (I, p. 113).

En la coemptio se llega in manum por una mancipatio, esto es, por cierta venta imaginaria.

La compraventa romana -denominada emptio et uenditio-, en realidad ofrecía la respuesta correcta, no a partir de la venta, sino de la compra, coemptio, derivada del verbo latino coemo y su supino coemptum.

Formaciones descriptivas se encuentran en voces como mancipatio:

unde etiam mancipatio dicitur, quia manu res capitur (I, p. 121).

de donde, ciertamente, se llama mancipatio porque se toma una cosa con la mano. 
Este sentido, al decir de Ernout y Meillet proviene del término legal mancipium, nombre del derecho de propiedad, y el verbo mancipo, vender. El origen de esta palabra no es del todo cierto y solo se cuenta con las relaciones que los mismos romanos establecían entre la manus y el verbo capio. Por su parte, Raimundo de Miguel acepta este origen (1897, p. 552).

En materia numeraria, por su parte, Gayo realiza dos apuntes acertados. El primero de ellos respecto de una de las monedas romanas, los dupondii:

Nam initio et asses librales erant et dupondii uere bilibres, unde etiam dupondius dictus est, quasi duo pondo; quod nomen adhuc in usu retinetur; semisses quoque et quadrantes pro rata scilicet portione ad pondus examinati erant (I, p. 122).

pues al inicio, los asses era de una libra y los duponii de dos libras, de donde, en efecto, se les llama dupondius, es decir, "dos libras"; nombre que todavía se mantiene en uso; los semiasses también y los cuadrantes, efectivamente, también eran examinados mediante su peso proporcional.

El segundo, por su parte, trata del esclavo encargado del manejo del dinero (algo semejante a nuestros cajeros modernos), de quienes refiere:

Quam ob rem qui dabat olim pecuniam non numerabat eam sed appendebat; unde serui quibus permittitur administratio pecuniae, dispensatores appellati sunt et adhuc uocantur (I, p. 122).

Porque quien antiguamente daba dinero no lo contaba, sino que lo pesaba; de donde los esclavos a quienes se les permite la administración del dinero se les llamó dispensatores (pesadores) y todavía se les llama así.

La relación etimológica entre dispensum y pensum es correcta, sin embargo, es curioso el periplo establecido a través del verbo appendo, pesar, al que está vinculado dispenso, entendido como distribuir luego de haber pesado las cosas. Aquí, mediante el sufijo -tor se ha obtenido el sustantivo correspondiente al actor.

Sobre el concepto de "legítimo" y su relación con lex Gayo efectúa una sencilla reflexión a propósito de la tutela legítima:

Ipsa tutela legitima uocatur, non quia nominatim ea lege de hac tutela cauetur, sed quia proinde accepta est per interpretationem, atque si uerbis legis introducta esset (I, p. 165).

Dicha tutela se llama legítima, no porque se le diga así en la ley en la que se prevé sobre tutela, sino porque ha sido aceptada por interpretación, como si hubiera sido introducida por las palabras de la ley. 
El sufijo -timus expresa, como es sabido, el sentido de relación, pertenencia u origen.

Como último apunte en esta materia dentro de este primer comentario, figura el "tutor pretorio", así denominado aquel que representaba a una mujer o un pupilo en sus juicios contra sus correspondientes tutores, en estos casos, dado el conflicto de intereses:

Alius dabatur, quo auctore legis actio perageretur, qui dicebatur praetorius tutor, quia a praetore urbano dabatur (I, p. 184).

Se daba otro, mediante el cual se realizaba la acción de ley, a quien se le llamaba tutor praetorius, porque era nombrado por el pretor urbano.

En realidad el sufijo -orius no expresa tanto lo que Gayo entiende, a saber, que el pretor -en este caso, urbano- lo haya nombrado, cuanto su vínculo con la función pretoriana.

\subsection{Comentario segundo}

El comentario segundo desarrolla el tema del derecho de las cosas y, a la vez, ofrece también once nuevas referencias de carácter etimológico a lo largo del examen.

Principia con la usureceptio, uno de los distintos tipos de usucapión:

Quae species usucapionis dicitur usureceptio, quia id quod aliquando habuimus, recipimus per usucapionem (II, p. 59).

La usureceptio se considera un tipo de usucapión, porque aquello que en alguna ocasión tuvimos, lo recibimos nuevamente por usucapión.

En realidad, la etimología de esta palabra no deriva de usucapio, pero sí de la construcción analógica de esta última, de donde ambas voces están emparentadas a través del término usus (uso). Propiamente, se compone de este significante y el supino del verbo recipere, receptum, en el sentido de recuperar, al que se le ha añadido el sufijo -tio.

Dentro de esta misma temática aparece la segunda referencia etimológica, la praediatura, de la que señala:

Et hoc est, quod uulgo dicitur ex praediatura possessionem usurecipi; nam qui mercatur a populo praediator appellatur (II, p. 61). 
Y esto es lo que vulgarmente se conoce como usureceptio de la posesión por praediatura, porque quien compra algo al pueblo recibe el nombre de praediator.

Aunque, praediator y praediatura derivan de praedium, es lo cierto que praediatura se construye mediante el sufijo -tura, que expresa relación u oficio para la formación de otros sustantivos a partir de esta misma categoría gramatical.

A continuación, este comentario desarrolla los principios del derecho testamentario romano. De entre este derecho, Gayo rescata el término procinctu:

Id est cum belli causa arma sumebant; procinctus est enim expeditus et armatus exercitus (II, p. 101).

Esto es porque tomaban las armas por causa de la guerra; procinctus est, ciertamente, el ejército armado y preparado.

En realidad, proviene del participio pasivo procinctus, procincta, procinctum, producto del verbo procingo, procinctum, prepararse para el combate.

Tal práctica del testamento militar ha sobrevivido hasta la actualidad. Más conceptual es la siguiente explicación del heredero necesario:

Necessarius heres est seruus cum libertate heres institutus, ideo sic appellatus, quia siue uelit siue nolit, omni modo post mortem testatorius protinus liber et heres est (II, p. 153).

Heredero necesario es el esclavo instituido heredero y declarado libre, por lo que así se le llama, ya que quiera o no quiera, de todos modos, después de la muerte del testador, es libre y heredero de inmediato.

"Quiéralo o no", siue uelit siue nolit, de allí deriva su condición de necesario. La misma idea se repite poco después a propósito de los herederos de derecho propio, aunque se ve complementado:

Sed sui quidem heredes ideo appellantur, quia domestici heredes sunt et uino quoque parente quodammodo domini existimantur; unde etiam si quis intestatus mortuus sit, prima causa est in successione liberorum. Necessarii uero ideo dicuntur, quia omni modo siue uelint siue nolint, tam ab intestato quam ex testamento heredes fiunt (II, p. 157).

Los herederos por derecho propio se llaman así porque son herederos domésticos y son considerados como dueños en vida de sus amos, de donde si este muere intestado, sus descendientes están en sucesión en el primer orden. Se les llama necesarios porque, de todos modos, lo quieran o no, tanto abintestato como con testamento son herederos. 
En el caso del heres sui iuris aparece una primera explicación (se consideran como domini), la que se ve complementada con su carácter necesario, el que aquí, no solo procede de la incidencia de la voluntad, sino de una situación lógica: por testamento o ab intestato, donde se aplica el principio de tercero excluido.

Por su parte, la cretio, así denominado el término que la ley otorga a los herederos extraños para decidir si aceptan la herencia o no, se indica que:

Ideo autem cretio appellata est, quia cernere est quasi decernere et constituere (II, p. 164).

De donde se le llama cretio, porque cernere es como discernir y decidir.

Efectivamente, esta voz procede del verbo latino cerno, merced a su supino cretum y el sufijo -tio.

La cretio puede ser continua o vulgar:

Continua haec cretio uocatur, quia continui dies numerantur. Sed quia tamen dura est haec cretio, altera magis in usu habetur; unde [etiam] uulgaris dicta est (II, pp. 172-173).

Se llama a esta cretio continua, porque se cuentan los días continuos. Pero, dado que esta cretio es difícil, la otra se usa más, por lo que se le conoce como vulgar.

Aquí el vínculo continualcontinuus es evidente; en cambio, lo uulgaris se relaciona con la generalización del uso, en oposición al derecho.

Siempre en el ámbito del derecho sucesorio, destaca el legado per uindicationem, la primera de las cuatro formas para asignar un legado:

Ideo autem per uindicationem legatum appellatur, quia post aditam hereditatem statim ex iure Quiritium res legatarii fit; et si eam rem legatarius uel ab herede uel ab alio quocumque qui eam possidet petat, uindicare debet, id est intendere suam rem ex iure Quisitium esse (II, p. 194).

El legado per uindicationem es llamado así porque, después de aceptar la herencia, la cosa se hace del legatario inmediatamente por derecho quiritario; y si el legatario la reclama de un heredero o de cualquier otro que la posea, debe reinvindicarla, esto es, afirmar que es suya por derecho quiritario. 
Claramente queda establecida la relación de este legado con el procedimiento de la uindicatio, tal y como apunta el autor, consistente en una reclamación de una cosa como propia, uindico, verbo al que se ha agregado el sufijo - tio referente a la acción.

Nuevamente, Gayo recurre a la etimología respecto de la cuarta forma de los legados, el per praeceptionem:

Praecipere enim esse praecipuum sumere; quod tantum in eius persona procedit qui aliqua ex parte heres institutus est, quod is extra portionem hereditatis praecipuum legatum habiturus sit (II, p. 217).

Praecipere es tomar con preferencia, lo que solo procede respecto de la persona que ha sido instituido heredero de una parte, pues él tendrá preferentemente su porción legada fuera de la herencia.

En realidad, praeceptio y praecipio forman parte de una misma familia léxica derivada de prae- y capio. Sin embargo, propiamente esta significante deriva de la forma verbal praecipio, en el sentido de ordenar, prescribir.

Cierra el comentario la referencia al legatarius partiarius:

Eius legatarii cui pars bonorum legatur; quae species legatis partitio uocatur; quia cum herede legatarius partitur hereditatem (II, p. 254).

Esto es, se le lega una parte de los bienes a quien es su legatario, lo cual es un tipo de legado que se llama partitio, porque el legatario dividirá la herencia con el heredero.

Nuevamente, las voces involucradas (partiarius, partitio y partitur) forman parte de una misma familia léxica, empero, el significante del que proceden es pars, parte.

\subsection{Comentario tercero}

Con doce referencias, el comentario tercero inicia con la etimología de la denominación de Latini Iuniani, latinos junianos, cuya apelación deriva de la Lex Iunia, la Ley Junia (III, p. 56):

Quia per legem Iuniam liberi facti sunt, etiamsi non essen ciues Romani.

Porque se hicieron libres por la Ley Junia, aunque no sean ciudadanos romanos. 
A la altura del parágrafo 90 destaca una de las etimologías más simpáticas, se trata del mutuo o préstamo de consumo. Este tiene lugar, por ejemplo, con el préstamo de azúcar entre vecinos, donde quien pide el bien no devuelve el mismo producto, sino algo equivalente. De este Gayo señala:

Vnde etiam mutuum appellatum est, quia quod ita $<\mathrm{ti}>$ bi a me datum est, ex meo tuum fit (III, p. 90).

De donde, ciertamente, se le llama mutuo, porque lo que a ti te he dado, se hace tuyo en virtud mía.

En realidad, pese a lo apropiado de la imagen gráfica transmitida, la etimología correcta del mutuum es el verbo muto, cambiar (en este sentido Ernout y Meillet, 1959, pp. 426-427).

Por su parte, del verbo spondeo, prometer, indica que proviene del griego (III, p. 93), aunque no señale la voz correspondiente. Posiblemente, se trate del término $\sigma \pi \circ \delta \delta \eta$, tratado, pacto, convenio (Pabón, 1995, p. 541). Para Raimundo de Miguel, en cambio, procede del verbo $\sigma \pi \varepsilon ́ v \delta \omega$ (1897, p. 876), pactar, concluir, estipular (Pabón, 1995, p. 541).

También en este campo, al tratar las formas cómo se adquieren las obligaciones, apunta sobre las obligaciones por el consentimiento:

Ideo autem istis modis consensu dicimus obligationes contrahi, quia neque uerborum neque scripturae ulla proprietas desideratur, sed sufficit eos qui negotium gerunt consensisse (III, p. 136).

En cambio, decimos que se contraen obligación por el consenso, ya que no se requiere ninguna formalidad de palabras o de documentos, pues basta que aquellos que hacen el negocio hayan consentido.

Por su parte, de las arras señala:

Nam quod arrae nomine datur, argumentum est emptionis et uenditionis contractae (III, p. 139).

Pues lo que se da recibe el nombre de arras, ya que son la prueba de la compra y venta contraídas.

En latín, arrae significa arras, fianza, garantía, prenda (Segura-Munguía, 2003, p. 57). Este significado, así como el lema, son un hebraísmo llegado a través del término griego ả $\rho \propto \beta \omega ́ v$, que significa arras; prenda, fianza (Pabón, 1995, p. 87). En el caso de este autor romano, se trata de una sinécdoque. 
Igualmente en el ámbito de las obligaciones, desarrolla las obligaciones quirografarias y las síngrafas así:

Praeterea litterarum obligatio fieri uidetur chirographis et syngraphis, id est si quid debere se aut daturum se scribat, ita scilicet si eo nomine stipulatio non fiat (III, p. 134).

Además, se considera que hay obligación por los documentos en los quirógrafos y síngrafos, esto es, si lo que se debe o se ha de dar ha sido escrito, es decir, si no se hace una estipulación con ese nombre.

En efecto, la denominación de chirographus significa etimológicamente, escrito a mano, en

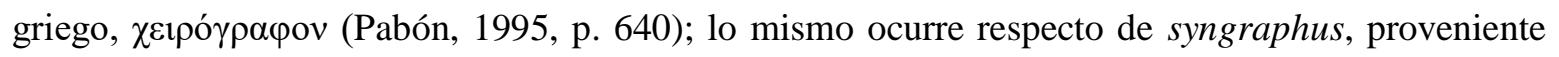

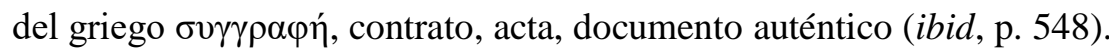

Respecto de la sociedad ercto non cito, la cual tenía lugar entre los herederos al morir el pater familias, señala:

Id est dominio non diuiso; erctum enim dominium est, unde erus dominus dicitur; ciere autem diuidere est, unde caedere et secare [et diuidere] dicimus (III, p. 154a).

Esto es, dominio no dividido; erctum es dominio, de donde se llama erus al dueño; ciere, en cambio, es dividir, de donde decimos cortar, partir y dividir.

En realidad, erctum no significa dominium, es el supino del verbo hercisco, dividir, en especial, la herencia (Ernout y Meillet, 1959, p. 200). La forma forma verbal cito, en cambio, es el frecuentativo de cieo y cio, y significa hacer comparecer ante la justicia, es decir, dividir judicialmente.

Nuevamente, en cuanto a contraer obligaciones, llama la atención aquella per aes et libram, la cual debe su nombre a que se realiza portando una balanza y una libra, las que intervienen en el ceremonial correspondiente (III, p. 173).

Cierra este interesante comentario el hurto no manifiesto (furtum nec manifestum), resultado de una operación lógica:

Nec manifestum furtum quid sit, ex iis quae diximus intellegitur; nam quod manifestum non est, id nec manifestum est (III, p. 185).

Lo que es el hurto nec manifestum, se entiende de aquellos que hemos explicado; pues lo que manifiesto no es, eso es nec manifestum.

Inmediatamente se explican los hurtos conceptum y oblatum: 
Conceptum furtum dicitur, cum apud aliquem testibus praesentibus furtiua res quaesita et inuenta est; nam in eum propria actio constituta est, quamuis fur non sit, quae appellatur concepti. Oblatum furtum dicitur, cum res furtiua tibi ab aliquo oblata sit eaque apud te concepta sit; utique si ea mente data tibi fuerit, ut apud te potius quam apud eum qui dederit conciperetur; nam tibi, apud eum qui dederit conciperetur; nam tibi, apud quem concepta est, propria aduersus eum qui obtulit, quamuis fur non sit, constituta est actio, quae appellatur oblati (III, pp. 186-187).

Se llama hurto conceptum, cuando se busca y encuentra la cosa robada ante algunos testigos presentes; pues se ha establecido una acción propia contra aquél, aunque no sea ladrón, la cual se llama furti concepti. Se llama hurto oblatum cuando la cosa robada por otro te la han ofrecido a ti y se encuentra en tu casa; porque si te fue dada con la intención de que era mejor que se encontrara en tu casa, en lugar de la de quien te la dio. Se te concede una acción contra quien te ofreció la cosa, aunque no sea el ladrón, la cual se llama furti oblati.

Efectivamente, el furtum conceptum deriva del participio pasivo del verbo concipio, tomar enteramente, concebir, ya que se ha realizado con plenitud, al tener el ladrón el objeto en su poder. Paralelamente, el furtum oblatum proviene del supino del verbo offero, ofrecer, ya que el objeto robado se ha ofrecido y entregado primero.

\subsection{Comentario cuarto}

Concluye la obra con diecinueve explicaciones etimológicas en el cuarto comentario, empieza con las legis actiones, cuya denominación procede de la fuente que las ha creado tal y como se indica seguidamente:

Actiones quas in usu ueteres habuerunt, legis actiones appellabantur uel ideo quod legibus proditae erant (quippe tunc edicta praetoris quibus conplures actiones introductae sunt nundum in usu habebantur), uel ideo quia ipsarum legum uerbis accommodatae erant et ideo inmutabiles proinde atque leges observabantur (IV, p. 11).

Las acciones que usaron nuestros antepasados se llamaban legis actiones, ya porque hubieran surgido de las leyes (sin duda, porque los edictos del pretor todavía no estaban en uso, los cuales han introducido muchas acciones) o porque se acomodaron a las palabras de las leyes $y$, por que, se observaban casi como leyes inmutables. 
De vuelta en la materia que nos ocupa, este autor trata de la palabra condictio, que expresa la obligación de elegir un juez en un plazo determinado por la contraparte. Su origen parece ser el siguiente:

Condicere autem denuntiare est prisca lingua. Itaque haec quidem actio proprie condictio uocatur; nam actor aduersario denuntiabat, ut ad iudicem capiendum die XXX adesset. Nunc uero non proprie condictionem dicimus actiones in personam <esse, qua> intendimus dari nobis oportere; nulla enim hoc tempore eo nomine denuntiatio fit (IV, pp. 17b-18).

Condicere es denunciar en la lengua antigua, por lo que esta acción se llama propiamente condictio; dado que el actor denunciaba al adversario para que compareciera ante el juez dentro los siguientes treinta días. Ahora, no llamamos condictiones con propiedad a las acciones personales, por las que reclamamos que se nos debe dar una cosa, ya que actualmente no hay ninguna denuncia bajo esta denominación.

Ciertamentamente, mediante el sufijo -tio se ha formado este sustantivo a partir del verbo condico que significa demandar (Segura-Munguía, 2003, p. 148).

Pasa luego a referir el origen del stipendium, reclamado en varios ámbitos en materia de prenda:

Introducta est moribus rei militaris. Nam et propter stipendium licebat militi ab eo; qui aes tribuebat, nisi daret, pignus capere; dicebatur autem ea pecunia quae stipendii nomine dabatur, aes militare. Item propter eam pecuniam licebat pignus capere ex qua equus emendus erat, quae pecunia dicebatur aes equestre. item propter eam pecuniam ex qua hordeum equis erat conparandum; quae pecunia dicebatur aes hordiarium (IV, p. 27).

Se introdujo por las costumbres en el ámbito militar. Por el stipendium, se le permitía al soldado a quien se le debía dinero, si no se lo daba, tomar algo en prenda. Ese dinero que se entregaba en nombre del stipendium se llamaba aes militare. Igualmente, por el dinero con el que se compraría un caballo se le permitía tomar una prenda, dinero que se llamaba aes equestre. E igualmente por el dinero con el que se compraría el pienso del caballo, el que se denominaba aes hordiarium.

Tal y como se aprecia, la denominación del aes variaba en función del contexto en que tenía lugar, ya el militar, el ecuestre o el del pienso para el caballo.

En la clasificación de las fórmulas, ya de derecho, ya de hecho, Gayo explica:

Sed eas quidem formulas in quibus de iure quaeritur, in ius conceptas uocamus, quales sunt quibus intendimus nostrum esse aliquid ex iure Quiritium aut nobis 
dare oportere aut pro fure damnum <decidi oportere; sunt et > aliae in quibus iuris ciuilis intentio est. Ceteras uero in factum conceptas uocamus, id est in quibus nulla talis intentionis conceptio est, <sed> initio formulae nominato eo quod factum est, adiciuntur ea uerba, per quae iudici damnandi absoluendiue potestar datur... (IV, pp. 45-46).

Pero aquellas fórmulas en las que se discute sobre el derecho, las llamamos fundamentadas in ius, por las cuales sostenemos que algo es nuestro por el derecho quiritario o que se nos debe dar o que conviene reparar un daño por furtum, son algunas en las que la intentio es de derecho civil. Las demás las llamamos basadas in factum, esto es, en las que no hay ninguna idea de intentio, pero al inicio de la fórmula se llama así porque hay un hecho y se agregan las palabras por las que se da la potestad de condenar o absolver...

Respecto de las actio exercitoria e institoria señala:

Ideo autem exercitori actio appellatur, quia exercitor uocatur is, ad quem cottidianus nauis quaestus peruenit (IV, p. 71).

En cambio, se llama actio exeritoria, porque se llama exercitor a quien empieza en el negocio cotidiano de la navegación.

Y prosigue:

Ideo autem institoria uocatur, quia qui tabernae praeponitur, institor appellatur (ibid).

Se llama institoria, porque quien se encarga de una taberna se llama institor.

De la jerga judicial romana, alude a la relación existente en los iudicia y el imperium así:

Ideo autem imperio contineri iudicia dicuntur, quia tamdiu ualent, quamdiu is qui ea praecepit imperium habebit (IV, p. 105).

Se dice que los juicios están contenidos en el imperium, porque tienen autoridad mientras aquél que los ha prescrito tenga el imperium.

Hay un capítulo interesante sobre las partes de la fórmula:

De la replicatio, el derecho de réplica contra una actio, se indica:

Alia adiectione opus est adiuuandi actoris gratia; quae adiectio replicatio uocatur, quia per eam replicatur atque resoluitur uis exceptionis (IV, p. 126).

Es necesario apoyar al actor con otra adiectio, la cual se llama replicatio, pues por ella se replica y destruye la fuerza de la excepción. 
Tal y como se aprecia, nuevamente es mediante el sufijo de acción -tio que se ha creado este sustantivo a partir de un verbo.

Las praescriptiones, en cambio, procede de que:

Ante formulas praescribuntur, plus quam manifiestum est (IV, p. 132).

se escriben antes que las fórmulas, lo que es más que manifiesto.

Ya de procesos específicos se explica el llamado interdicto sectorio:

Item ei qui publica bona emerit, eiusdem condicionis interdictum proponitur quod appellatur sectorium, quod sectores uocantur qui publice bona mercantur (IV, p. 146).

Igualmente a quien comprara bienes públicos, se le facilita un interdicto de tal condición, el cual se denomina sectorium, pues se llaman sectores quienes compran bienes públicamente.

En este mismo campo de los interdictos, se consideran los exhibitoria y restitutoria:

Namque actor est qui desiderat aut exhiberi aut restitui, reus is est a quo desideratur ut exhibeat aut restituat (IV, p. 157).

Pues actor es quien desea que se exhiba o restituya, reus es aquel a quien se pide que exhiba o restituya.

De los arbitrarios se indica:

Namque si arbitrum postulauerit is cum quo agitur, accipit formulam quae appellatur arbitraria (IV, p. 163).

Pues si pidiera un árbitro aquél con quien litiga, recibe la fórmula que se llama arbitraria.

Mediante el sufijo -arius, propio de la derivación nominal, se ha creado el adjetivo arbitraria.

En cuanto a su clasificación en dobles o simples:

Ideo autem duplicia uocantur, quod par utriusque litigatoris in his condicio est, nec quisquam praecipue reus uel actor intellegitur (IV, p. 160).

Se llaman dobles, porque cada uno de los litigantes están en una condición igual, y no se considera que uno $u$ otro sea mayoritariamente actor o demandado. 
En las etapas del proceso trata del juicio fructuario o secutorio:

Appellatur fructuarium, quo nomine actor iudicatum solui satis accipit. Dicitur autem et hoc iudicum secutorium, quod sequitur sponsionis uictoriam; sed non aeque Cascellianum uocatur (IV, p. 169).

Se llama fructuarium pues, según esta denominación, el actor recibe la orden de pago a satisfacción. Se le llama a este juicio secutorium, pues sigue a la promesa de victoria, pero no se llama igualmente Cascellianum.

Termina la obra en materia etimológica con los interdicta secundaria, es decir:

Quod secundo loco redduntur (IV, p. 170).

Pues tienen lugar en segundo lugar.

\section{Conclusiones}

Con el propósito de mostrar breve y de manera concisa los resultados del estudio, seguidamente se ofrece una tabla con la información obtenida:

COMMENTARIUS PRIMUS

\begin{tabular}{|c|c|c|}
\hline Voz & Etimología gayana & $\begin{array}{c}\text { Etimología correcta o } \\
\text { corregida }\end{array}$ \\
\hline ius ciuile & ius ciuitatis & ciuis \\
\hline ius gentium & omnes gentes eo utuntur & \\
\hline *spurius & $\sigma \pi о \rho \alpha ́ \delta \eta \nu$ & spurium/spurcus \\
\hline adrogatio & adoptans rogatur & arrogo $<a d+r o g o$ \\
\hline * confarreatio & Júpiter Farreo & confarreō, cum+farreum \\
\hline coemptio & imaginariam uenditionem & coemo, coemptum \\
\hline mancipatio & manu res capitur & mancipium \\
\hline dupondii & duo pondo & \\
\hline dispensatores & appendo & dispenso \\
\hline
\end{tabular}




\begin{tabular}{ll}
\hline legitimum & lex \\
\hline praetorius tutor & a praetore urbano dabatur \\
\hline
\end{tabular}

\section{COMMENTARIUS SECUNDUS}

\begin{tabular}{|c|c|c|}
\hline usureceptio & $\begin{array}{ll}\text { recipimus } & \text { per } \\
\text { usucapionem } & \end{array}$ & usu+receptio \\
\hline praediatura & praediator & \\
\hline procinctu & $\begin{array}{l}\text { procinctus } \quad \text { (armatus } \\
\text { exercitus) }\end{array}$ & procingo, procinctum \\
\hline $\begin{array}{l}\text { Necessarius } \\
\text { heres }\end{array}$ & siue uelit siue nolit & \\
\hline sui iuris heredes & $\begin{array}{l}\text { domestici sunt, modo } \\
\text { domini existimantur }\end{array}$ & \\
\hline cretio & cerno & cerno, cretum \\
\hline Cretio continua & continui dies numerantur & \\
\hline Cretio uulgaris & in usu habetur & \\
\hline $\begin{array}{l}\text { per } \\
\text { uindicationem }\end{array}$ & uindicare & \\
\hline $\begin{array}{l}\text { legatum per } \\
\text { praeceptionem }\end{array}$ & praecipuum & praecipio \\
\hline $\begin{array}{l}\text { legatarius } \\
\text { partiarius }\end{array}$ & partitio & pars \\
\hline
\end{tabular}

COMMENTARIUS TERTIUS

\begin{tabular}{lll}
\hline Latini Iuniani & Lex Iunia & \\
\hline mutuum & meum-tuum & muto \\
\hline spondeo & griego & $\sigma \pi 0 v \delta \eta ́-\sigma \pi \varepsilon ́ v \delta \omega$ \\
\hline $\begin{array}{l}\text { obligationes } \\
\text { consensu }\end{array}$ & sufficit consensisse & \\
\hline arrae & argumentum emptionis & $\alpha \rho \rho \alpha \beta \omega ́ v$ \\
\hline
\end{tabular}




\begin{tabular}{|c|c|}
\hline $\begin{array}{l}\text { obligatio } \\
\text { chirographis } \\
\text { syngraphis }\end{array}$ & $\begin{array}{l}\text { si quid debere se aut } \\
\text { daturum se scribat }\end{array}$ \\
\hline ercto non cito & $\begin{array}{l}\text { herctum }<\text { hercisco } \\
\text { cito }<\text { cieo }\end{array}$ \\
\hline $\begin{array}{l}\text { per aes et } \\
\text { libram }\end{array}$ & aes et libra \\
\hline $\begin{array}{l}\text { furtum nec } \\
\text { manifestum }\end{array}$ & $\begin{array}{l}\text { quod manifestum non est, } \\
\text { id nec manifestum est }\end{array}$ \\
\hline $\begin{array}{l}\text { furtum } \\
\text { conceptum }\end{array}$ & $\begin{array}{l}\text { furtiua res quaesita et concipio } \\
\text { inuenta est; nam in eum } \\
\text { propria actio constituta } \\
\text { est, quamuis fur non sit }\end{array}$ \\
\hline furtum oblatum & $\begin{array}{l}\text { tibi, apud quem concepta offero } \\
\text { est, propria aduersus eum } \\
\text { qui obtulit, quamuis fur } \\
\text { non sit, constituta est actio }\end{array}$ \\
\hline
\end{tabular}

\begin{tabular}{|c|c|}
\hline legis actiones & lex \\
\hline condictio & condico \\
\hline $\begin{array}{l}\text { aes militare, } \\
\text { equestre, } \\
\text { hordiarium }\end{array}$ & milites, equus, hordeum \\
\hline $\begin{array}{l}\text { formula in ius } \\
\text { concepta }\end{array}$ & de iure quaeritur \\
\hline $\begin{array}{l}\text { formula in } \\
\text { factum concepta }\end{array}$ & de facto quaeritur \\
\hline actio exercitoria & exercitor \\
\hline actio institoria & institor \\
\hline $\begin{array}{l}\text { iudicia contineri } \\
\text { imperium }\end{array}$ & $\begin{array}{ll}\text { ualent quamdiu is qui ea } \\
\text { praecepit } \\
\text { habebit }\end{array}$ \\
\hline replicatio & replico \\
\hline
\end{tabular}




\begin{tabular}{ll}
\hline praescriptiones & $\begin{array}{l}\text { ante formulas } \\
\text { praescribuntur }\end{array}$ \\
\hline $\begin{array}{l}\text { interdictum } \\
\text { sectorius }\end{array}$ & $\begin{array}{l}\text { sectores uocantur qui } \\
\text { publice bona mercantur }\end{array}$ \\
\hline exhibitoria & exhiberi \\
\hline restitutoria & restitui \\
\hline arbitraria & arbitrum \\
\hline duplicia & $\begin{array}{l}\text { quod par utriusque } \\
\text { litigatoris in his condicio } \\
\text { est }\end{array}$ \\
\hline secutorium & $\begin{array}{l}\text { quod sequitur sponsionis } \\
\text { uictoriam }\end{array}$ \\
\hline $\begin{array}{l}\text { interdicta } \\
\text { secundaria }\end{array}$ & $\begin{array}{l}\text { quod secundo loco } \\
\text { redduntur }\end{array}$ \\
\hline
\end{tabular}

Del anterior examen se colige que, a pesar del manejo casi intuitivo de la gran mayoría de las etimologías ofrecidas, un alto porcentaje son exitosas. El número de falsas etimologías es bastante reducido, lo que contrasta con un número un poco más alto de etimologías que debieron o convenía precisarse.

Claramente, se aprecia que el comentario cuarto ofrece la mayor precisión en el desarrollo etimológico, ya que todas eran correctas.

Ahora bien, el presente estudio rescata, a su vez, la importancia del estudio del significado de las palabras para los juristas, tanto en el pasado como en la actualidad, para cuyo desarrollo el área etimológica representa un espacio sumamente relevante. 


\section{Referencias bibliográficas}

De Miguel, Raimundo. (1897). Nuevo diccionario latino-español etimológico. Prólogo de Luis Alberto de Cuenca (11. a ed. corregida y aumentada). Madrid: Sáenz De Jubera, Hermanos Editores.

Ernout, A. y Meillet, A. (1959). Dictionnaire Étimologique de la Langue Latina (4. ${ }^{\mathrm{a}}$ ed.). París: Libraire C. Klicksieck.

Gayo. (1990). Instituciones. Edición bilingüe. Reimpresión. Madrid: Editorial Civitas.

Pabón S. de Urbina, José M. (1995). Vox. Diccionario manual griego-español (17.a ed.). Barcelona: Bibliograf.

Real Academia de la Lengua Española. (2001). Diccionario de la lengua española (22. ${ }^{\text {a }}$ ed.). España: Editorial Espasa Calpe.

Segura Munguía, Santiago. (2003). Nuevo diccionario etimológico Latín-Español y de las voces derivadas (1. a reimpresión). Bilbao: Universidad de Deusto.

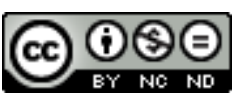

Esta obra está bajo una licencia de Creative Commons Reconocimiento-NoComercialSinObraDerivada 4.0 Internacional 